\title{
Key to Opening Kidney for In Vitro-In Vivo Extrapolation Entrance in Health and Disease: Part II: Mechanistic Models and In Vitro-In Vivo Extrapolation
}

\author{
Daniel Scotcher, ${ }^{1}$ Christopher Jones, ${ }^{2}$ Maria Posada, ${ }^{3}$ Aleksandra Galetin, ${ }^{1}$ and Amin Rostami-Hodjegan ${ }^{1,4,5}$
}

Received 6 July 2016; accepted 11 July 2016; published online 9 August 2016

\begin{abstract}
It is envisaged that application of mechanistic models will improve prediction of changes in renal disposition due to drug-drug interactions, genetic polymorphism in enzymes and transporters and/or renal impairment. However, developing and validating mechanistic kidney models is challenging due to the number of processes that may occur (filtration, secretion, reabsorption and metabolism) in this complex organ. Prediction of human renal drug disposition from preclinical species may be hampered by species differences in the expression and activity of drug metabolising enzymes and transporters. A proposed solution is bottom-up prediction of pharmacokinetic parameters based on in vitro-in vivo extrapolation (IVIVE), mediated by recent advances in in vitro experimental techniques and application of relevant scaling factors. This review is a follow-up to the Part I of the report from the 2015 AAPS Annual Meeting and Exhibition (Orlando, FL; 25th-29th October 2015) which focuses on IVIVE and mechanistic prediction of renal drug disposition. It describes the various mechanistic kidney models that may be used to investigate renal drug disposition. Particular attention is given to efforts that have attempted to incorporate elements of IVIVE. In addition, the use of mechanistic models in prediction of renal drugdrug interactions and potential for application in determining suitable adjustment of dose in kidney disease are discussed. The need for suitable clinical pharmacokinetics data for the purposes of delineating mechanistic aspects of kidney models in various scenarios is highlighted.
\end{abstract}

KEY WORDS: active renal excretion; human kidney transporters; human renal drug clearance; kidney disease; non-hepatic drug metabolism.

\section{INTRODUCTION}

Renal metabolism and excretion can be important determinants of the local and systemic exposures of drugs and their metabolites. The rates at which drugs and metabolites are

Electronic supplementary material The online version of this article (doi:10.1208/s12248-016-9959-1) contains supplementary material, which is available to authorized users.

\footnotetext{
${ }^{1}$ Centre for Applied Pharmacokinetic Research, Manchester Pharmacy School, University of Manchester, Stopford Building, Oxford Road, Manchester, M13 9PT, UK.

${ }^{2}$ DMPK, Oncology iMed, AstraZeneca R\&D Alderley Park, Macclesfield, Cheshire, UK.

${ }^{3}$ Drug Disposition, Lilly Research Laboratories, Indianapolis, Indiana 46203 , USA.

${ }^{4}$ Simcyp Limited (a Certara Company), Blades Enterprise Centre, Sheffield, UK.

${ }^{5}$ To whom correspondence should be addressed. (e-mail: amin.rostami@manchester.ac.uk)
}

excreted from the blood and tubular cells into urine are determined by various processes: glomerular filtration, active transport into and out of proximal tubule cells, and passive permeation across the nephron tubular epithelium. These processes can be experimentally studies using a variety of available in vitro techniques and systems, as described in Part I of this review (1). However, quantitative translation of information obtained from these in vitro systems using physiologically based pharmacokinetic (PBPK) models is currently incomplete. PBPK models are widely used during drug development to address a variety of systems pharmacology questions, and can be integrated with the in vitro-in vivo extrapolation (IVIVE) paradigm (2). Mechanistic organ models, which may be incorporated into PBPK models, can be used to account for the interplay of enzymes, transporters and binding proteins/ lipids that determine drug concentrations of cells, tissues and biological fluids. Mechanistic kidney models rely upon in-depth quantitative knowledge of renal physiology to inform the many different system parameters. Literature analysis of many of the relevant elements of renal physiology was discussed in detail in Part I of this review (1). 
The IVIVE approach uses physiologically relevant scaling factors to scale in vitro data to the level of the tissue or organ. As discussed below, these scaling factors are often determined by measuring particular biological differences between the in vitro system and the tissue/organ (or other in vitro systems), but can also be determined in a more empirical manner using clinical data. While other methods for prediction of pharmacokinetic parameters, such as quantitative structure-activity relationships (QSAR) and scaling from preclinical species, may give adequate prediction accuracy, IVIVE approaches based on physiological assumptions are favourable because of the mechanistic basis and advantages this approach brings (2). Further, species differences in the function, expression or localisation of drug metabolising enzymes and transporters in kidney is a potential limitation of the interspecies scaling approach for certain drugs. In particular, the human $\mathrm{CL}_{\mathrm{R}}$ for several drugs was poorly predicted based on rat $C L_{R}$, even after species differences in $\mathrm{f}_{\mathrm{u}, \mathrm{p}}$ and kidney blood flow had been accounted for (3). No rat homologue exists for multidrug and toxin extrusion $2-\mathrm{K}$ (MATE2-K/SLC47A2) which is expressed at the apical membrane of the proximal tubule cells in human kidney. Furthermore, a number of organic anion transporting polypeptides (OATP) are expressed at the apical membrane of proximal tubule cells in rat (e.g. Oatp1a1 [Slc21a1], Oatp1a3 [Slc21a4], Oatp1a6 [Slc21a13] and Oatp4c1 [Slc21a20; conflicting evidence concerning apical or basolateral membrane localisation]), whereas OATP4C1 (SLC21A20) is expressed at the basolateral membrane of proximal tubule cells in human (Part I, Table II (1)). Validated mechanistic models have the advantage in their ability to predict the impact of pathophysiological changes, such as those encountered in chronic kidney disease, or in population sub-groups that have not been investigated in clinical studies. As a high proportion of drugs (>40\%) approved in 2013 and 2014 did not have dose recommendations for severe renal impairment (4), mechanistic models may guide the design of clinical studies and dose recommendations (5).

The overall aim of this part of the review is to examine the progress required to achieve quantitative predictions of renal drug disposition using PBPK-IVIVE with specific focus on the efforts to develop and validate mechanistic kidney models. This will include the prediction of renal drug metabolism and renal excretion as clearance routes. In addition, attempts to use mechanistic models to predict renal drug-drug interactions (DDI) and impact of kidney disease on renal drug elimination will be critically assessed. The need for generation of appropriate clinical data will be discussed and implications for modelling discussed.

There is an increasing interest in the developmental aspects of paediatric PBPK models, as illustrated in the recent paper from European Medical Agency (EMA) on extrapolation to paediatrics from adult data using mechanistic approaches (6). However, this topic is not discussed in the current review. Nonetheless, it is important to note that modelling of renal drug disposition in paediatrics requires special consideration to account for the maturation of renal function and ontogeny of protein expression. For those interested in this topic, modelling efforts and reviews have previously been reported (7-9). Another topic outside the scope of the current review is research into renal disposition in preclinical species. In this respect, it is important to recognise that such research (e.g. knock-out mouse models) can be used to understand the contributions of individual transporter in the tubular excretion of drugs, and assessment of the ratelimiting step (influx $v s$. efflux) in tubular drug secretion (10).

\section{USE OF MODELS FOR STUDYING PHARMACOKINETICS IN KIDNEY: CURRENT STATUS AND IVIVE OPPORTUNITIES}

Mechanistic models of renal drug excretion, static or dynamic, need to account for the overall anatomical organisation of the nephron. Various mechanistic kidney models have been reported that allow simulation of different processes (filtration, metabolism, transport, passive permeation) individually and in combination. In general, static models typically consider filtration, secretion and/or reabsorption in isolation and as separate mechanisms contributing to overall $\mathrm{CL}_{\mathrm{R}}$ (11-13). Conversely, dynamic models that are comprised of compartments representing physiological spaces (e.g. plasma, cells, tubular filtrate) support simulation of drug concentrations within these spaces. This allows for metabolism, passive permeability and various transport processes to be considered simultaneously (14). Understanding of intracellular drug and metabolite concentrations through simulation can provide important insight into potential liabilities with respect to nephrotoxicity and DDIs that might otherwise not be obtained from clinical data alone.

\section{Prediction of Renal Drug Metabolism Within PBPK Paradigm}

The scaling of in vitro microsomal metabolism data using the microsomal protein content as IVIVE scaling factor is widely used for scaling of hepatic metabolism data (15). This approach has also been adopted for the IVIVE of renal drug metabolism (Table I). Overview of relevant in vitro systems and corresponding scaling factors was discussed in detail previously (1). Although a lack of suitable clinical data for assessment of IVIVE-based predictions of renal drug metabolism is a profound limitation (see below for details), several examples of IVIVE of human kidney microsomal metabolism data have been reported, mostly within the last decade. Chronological data shown in Fig. 1 illustrate that microsomal protein content measured in human liver, rat liver and rat kidney were used for IVIVE of human kidney microsomal metabolism data up until 2006. Since then, a microsomal protein per gram kidney (MPPGK) value of $12.8 \mathrm{mg} / \mathrm{g}$ has most commonly been used, which is substantially lower than the values reported for human liver $(25,26)$. Scaling of in vitro data generated in $\mathrm{S} 9$ and cytosol fractions is through analogous scalars (S9 protein (S9PPGK) and cytosolic protein (CPPGK) per gram of kidney; Table I). Due to a lack of CPPGK data, the combination of the human MPPGK and the liver cytosolic scaling factor has been applied for the IVIVE of renal hydrolysis clearance data (e.g. mycophenolate mofetil) generated in S9 fractions (16).

The scaling of in vitro data generated in recombinantly expressed enzyme systems is performed using the relative expression factor (REF), relative activity factor (RAF) or inter-system extrapolation factor (ISEF) scaling factors (Table I). Enzyme abundances were found to be between 7- and 11 -fold and 19- and 43-fold higher in recombinant expression 
Table I. Summary of Scaling Factors Proposed for IVIVE of Renal Drug Disposition

\begin{tabular}{|c|c|c|}
\hline Scalar (abbreviation) [units] & Type of in vitro data to scale (units) & Literature values and applications \\
\hline $\begin{array}{l}\text { Microsomal or cytosolic protein } \\
\text { per gram kidney } \\
\text { (MPPGK or CPPGK) } \\
\text { [mg protein/g kidney] }\end{array}$ & $\begin{array}{l}\text { Metabolic activity }{ }^{\mathrm{a}} \\
\text { (per } \mathrm{min} / \mathrm{mg} \mathrm{microsomal} \mathrm{or} \\
\text { cytosolic protein) }\end{array}$ & $\begin{array}{l}\text { - MPPGK-12.8 mg/g commonly used } \\
\text { (Fig. 1), mostly applied to glucuronidation. } \\
\text { See also Part I, Table V (1) } \\
\text { - CPPGK—no relevant studies found }\end{array}$ \\
\hline $\begin{array}{l}9000 \text { g supernatant }(\mathrm{S} 9) \text { protein } \\
\text { per gram kidney (S9PPGK) } \\
\text { [mg protein/g kidney] }\end{array}$ & $\begin{array}{l}\text { Metabolic activity } \\
\quad(\text { per min/mg S9 protein) }\end{array}$ & $\begin{array}{l}\text { - } 121 \text { (value for liver) and } 93.5 \mathrm{mg} / \mathrm{g} \text { kidney } \\
\text { (based on MPPGK }(12.8 \mathrm{mg} / \mathrm{g} \text { ) } \\
\text { and CPPGL }(80.7 \mathrm{mg} / \mathrm{g})) \text { used to scale } \\
\text { hydrolysis } \mathrm{CL}_{\text {int }} \text { data from kidney S9 (16) }\end{array}$ \\
\hline $\begin{array}{l}\text { Relative expression factor (REF) } \\
\text { [Dimensionless, or refers to } \\
\text { different scales data } \\
\text { may be normalised to } \\
\text { (e.g. mg protein/million cells)] }\end{array}$ & $\begin{array}{l}\text { Activity }{ }^{\mathrm{a}} \text { in expression systems }{ }^{\mathrm{b}} \\
\text { (per } \mathrm{min} / \mathrm{mg} \text { microsomal protein; } \\
\text { per } \mathrm{min} / \mathrm{mg} \text { protein; per min/million } \\
\text { cells; per } \mathrm{min} / \mathrm{cm}^{2} \text { ) }\end{array}$ & $\begin{array}{l}\text { - rhUGT1A9 Supersomes: } 0.1 \text { (MHKM) (17) } \\
\text { - rhUGT1A9 Supersomes: } 0.023 \text { (MHKM) (17) } \\
\text { - Empirically determined values }{ }^{\mathrm{c}} \text { of } 5.3 \\
\text { (HEK-OAT3, pemetrexed (18)), } 3 \text { and } 2.3^{\mathrm{d}} \\
\text { (HEK-OCT2, metformin (19)) from plasma } \\
\text { concentration data } \\
\text { - Empirically determined values }{ }^{\mathrm{c}} \text { of } 3 \text { and } 1^{\mathrm{d}} \\
\text { (HEK-MATE1, HEK-MATE2-K, metformin (19)), } \\
\text { from urinary excretion data }\end{array}$ \\
\hline $\begin{array}{l}\text { Relative activity factor (RAF) } \\
\text { [Dimensionless, or refers to } \\
\text { different scales data } \\
\text { may be normalised to } \\
\text { (e.g. mg protein/million cells)] }\end{array}$ & $\begin{array}{l}\text { Activity }^{\mathrm{a}} \text { in expression systems } \\
\text { (per } \mathrm{min} / \mathrm{mg} \text { microsomal protein; } \\
\text { per } \mathrm{min} / \mathrm{pmol} \text { of specific protein; } \\
\text { per } \mathrm{min} / \mathrm{mg} \text { protein; per min } / \text { million } \\
\text { cells; per } \mathrm{min} / \mathrm{cm}^{2} \text { ) }\end{array}$ & 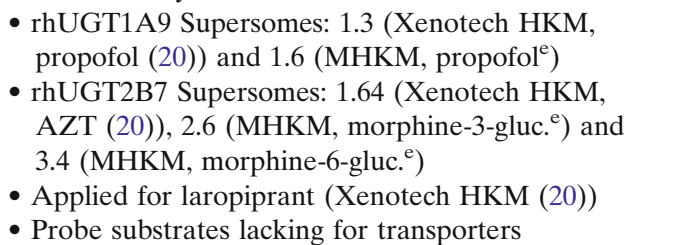 \\
\hline $\begin{array}{l}\text { Absolute protein expression } \\
\text { or abundance scalar } \\
\text { [pmol enzyme/mg protein] }\end{array}$ & $\begin{array}{l}\text { Activity }{ }^{\mathrm{a}} \text { in expression systems } \\
\text { (per } \mathrm{min} / \mathrm{pmol}^{\mathrm{b}} \text { protein) }\end{array}$ & $\begin{array}{l}\text { - Several studies for UGT1A6, 1A9 and 2B7 } \\
\text { (See Part I (1)) } \\
\text { - Data recently reported for renal transporters (21) }\end{array}$ \\
\hline $\begin{array}{l}\text { Inter-system extrapolation factor } \\
\text { (ISEF) } \\
\text { [Dimensionless] }\end{array}$ & $\begin{array}{l}\text { Activity }{ }^{\mathrm{a}} \text { in expression systems } \\
\text { (per } \mathrm{min} / \mathrm{pmol}^{\mathrm{b}} \text { protein) }\end{array}$ & 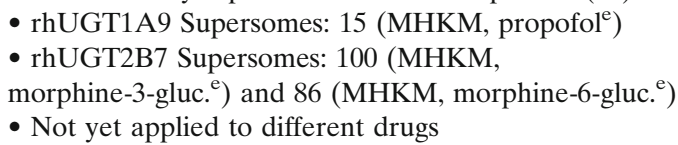 \\
\hline $\begin{array}{l}\text { Surface area } \\
{\left[\mathrm{cm}^{2}\right]}\end{array}$ & $\begin{array}{l}\text { Activity }^{\mathrm{a}}\left(\text { per } \mathrm{min} / \mathrm{cm}^{2}\right) \text { or permeability } \\
(\mathrm{cm} / \mathrm{s}) \text { across kidney cells }\end{array}$ & $\begin{array}{l}\text { - Applied for scaling } \mathrm{P}_{\text {app }} \text { data for passive tubular } \\
\text { reabsorption and secretion }(19,22,23)\end{array}$ \\
\hline $\begin{array}{l}\text { Proximal tubule cells } \\
\text { per gram kidney (PTCPGK) } \\
\text { [million PTC/g kidney] }\end{array}$ & $\begin{array}{l}\text { Activity in kidney cells }{ }^{\mathrm{g}} \\
\text { (per min/million cells) }\end{array}$ & $\begin{array}{l}\text { - Implemented in SimCYP MechKiM, but } \\
\text { physiological data lacking (14) } \\
\text { - Estimates range 30-09 million PTC/g kidney (1) }\end{array}$ \\
\hline $\begin{array}{l}\text { Kidney weight } \\
{[\mathrm{g}]}\end{array}$ & $\begin{array}{l}\text { Uptake into precision cut } \\
\text { kidney slices } \\
\mathrm{CL}_{\text {int }}(\mathrm{mL} / \mathrm{min} / \mathrm{g} \text { kidney })\end{array}$ & $\begin{array}{l}\text { - Application for kidney slice uptake resulted } \\
\text { in } 10 \text {-fold under-prediction (24) }\end{array}$ \\
\hline
\end{tabular}

$C L_{\text {int }}$ intrinsic clearance, $C P P G L$ cytosolic protein per gram of liver, $H E K$ human embryonic kidney cells, $H K M$ human kidney microsomes, $M A T E$ multidrug and toxin extrusion transporter, MechKiM mechanistic kidney model in SimCYP simulator, $M H K M$ mixed (i.e. cortex and medulla) human kidney microsomes, $O A T$ organic anion transporter, $O C T$ organic cation transporter, $P_{a p p}$ apparent permeability, $(r h) U G T$ (recombinantly expressed human) uridine glucuronosyltransferase

${ }^{a}$ Activity includes intrinsic clearance $\left(\mathrm{CL}_{\mathrm{int}} ; \mu \mathrm{L} / \mathrm{min} /\right.$ ? $)$ and maximum rate of reaction $\left(\mathrm{V}_{\max } ; \mathrm{nmol} / \mathrm{min} /\right.$ ? $)$, where ? depends on the way data are normalised (e.g. per mg protein or per million cells etc.)

${ }_{b} \mathrm{REF}=\frac{I n \text { vivo expression or abundance }}{\text { In vitro expression or abundance }}, \mathrm{RAF}=\frac{I n \text { vivo activity }}{\text { In vitro activity }}$ and ISEF $=\frac{I n \text { vivo activity }}{\text { In vitro activity } \times \text { Protein abundance in vivo }}$, in vitro expression systems are recombinantly expressed drug metabolising enzymes, and transfected cell lines and derived membrane vesicles

${ }^{c}$ Empirically determined scalar may also be identified as RAF

${ }^{d}$ Before and after model refinement accounting for electrogenic OCT2 mediated transport

${ }^{e}$ Calculated using data reported in Knights et al. (17)

${ }^{f}$ Permeability can be the apparent permeability $\left(\mathrm{P}_{\text {app }}\right)$ or be the membrane permeability $\left(\mathrm{P}_{\mathrm{mem}}\right)$, and may refer to the total drug or specifically the unionised/ionised drug

${ }^{g}$ In vitro kidney cells refers to immortalised kidney cell lines or primary cultured renal tubule cells

systems than in human kidney microsomes for uridine diphosphate glucuronosyltransferase (UGT) 1 A9 and UGT2B7, respectively $(17,27,28)$. These data suggest that for calculation of the appropriate REF values for IVIVE, enzyme abundance data should be collected for every batch of recombinantly expressed UGT. In addition, the presence of inactive forms of recombinant UGTs in insect cell expression systems may invalidate the assumption of proportional 
abundance-activity relationship, which the REF-based scaling relies upon $(17,29)$. These considerations, along with current challenges associated with quantitative proteomics (e.g. not common practice, technical challenges), suggest that a more pragmatic approach is to determine RAF using selective probe substrates. UGT probes have been proposed for UGT1A9 (e.g. propofol) and UGT2B7 (e.g. 3'-azidothymidine) $(20,30,31)$, although selectivity remains a challenge (1).

Perfusion rate-limited kidney models, analogous to those traditionally used for hepatic metabolism, have been applied for IVIVE of renal metabolic clearance $(17,20,25,32)$. This includes limited use of PBPK models, allowing for simulation of plasma concentration-time profiles (33). There is a trend for underprediction of overall glucuronidation clearance using IVIVE, even when both hepatic and renal glucuronidation are accounted for $(17,32,33)$. Use of the well-stirred model may bias IVIVE predictions for renal metabolism $(17,32)$, although no suitable alternative, kidney-specific, model has yet been proposed. Conversely, kidney-specific permeability-ratelimiting mechanistic models of drug metabolism, suitable for investigating excretion-metabolism interplay of drugs and metabolites (e.g. enalapril), have been reported $(34,35)$. In such models, the impact of co-localised expression (in the cortex or medulla, or particular tubular region) of relevant enzymes and transporters could be an important consideration. Therefore, although mixed kidney microsomes (containing both medulla and cortex) are proposed as suitable when using the well-stirred model (17), kidney cortex microsomes, as well as cortex-specific MPPGK, could be more appropriate for certain modelling tasks involving IVIVE, depending on the question of interest.

\section{Prediction of Renal Excretion of Drugs Within PBPK Paradigm}

Filtration clearance can be predicted relatively easily, from the glomerular filtration rate (GFR) and the fraction unbound of drug in plasma $\left(\mathrm{f}_{\mathrm{u}, \mathrm{p}}\right)$, whereas predicting secretion and/or reabsorption is more challenging. Various approaches for IVIVE of transporter mediated secretion or reabsorption have been proposed that allow for scaling of data from different in vitro assay formats (Table I). In order to scale $\mathrm{CL}_{\text {int }}$ or $\mathrm{V}_{\max }$ in vitro data, not only must appropriate scaling factors be available, but the in vitro data must be normalised (e.g. per mg protein, per million cells, etc.) in a way that allows for IVIVE. If $\mathrm{K}_{\mathrm{m}}$ values are available from in vitro experiments, these can typically be used directly as model parameters, providing appropriate analysis of the in vitro data has been performed, as discussed in Part I $(1,13,36,37)$. Another important consideration is that values for transporter kinetic parameters often differ widely between experimental systems and between laboratories, and this can translate into uncertainty in model parameters (38).

The scheme presented in Fig. 2 is the proposed approach for IVIVE of activity data generated using transfected cell lines that is implemented within the mechanistic kidney model (MechKiM) module of the SimCYP simulator. This approach uses the REF, PTCPGK and kidney weight scaling factors. PTCPGK is currently of limited use as a scaling factor due to a lack of relevant experimental data available (1). Likewise, the appropriate abundance data that are needed to calculate REFs for renal drug transporters (i.e. abundances in human kidney and in vitro systems) are lacking, and therefore the proposed IVIVE approach is not currently feasible (1). Instead, empirical optimisation of transporter activities or REF/RAF parameters using clinical data has been applied to adequately describe clinically observed $\mathrm{CL}_{\mathrm{R}}(18,19,39)$ (Table I). In some instances, as illustrated in the case of veliparib, REF scaling was not necessary for successful IVIVE of $C L_{R}$ (40). In this study. the uptake activity in $1 \mathrm{mg}$ protein in transfected HEK cells was assumed to be equivalent to the activity found in 1 million proximal tubule cells in vivo, although justification for this assumption was not given.

In contrast, sufficient physiological data are available for scaling in vitro data using surface area to predict $\mathrm{CL}_{\mathrm{R}, \mathrm{sec}}(22)$. The success of this approach may be hindered by any potential differences in the characteristics (e.g. protein expression, cell morphology) of the in vitro system and the kidney in vivo, if these are not accounted for. However, scaling of $\mathrm{P}_{\text {app }}$ data from the Lewis lung carcinoma pig kidney (LLC-PK1) cell line by surface area was used to predict $\mathrm{CL}_{\mathrm{R}}$ of net secreted drugs with reasonable success using the wellstirred model (22). $\mathrm{CL}_{\text {int }}, \mathrm{V}_{\max }$ (when expressed per $\mathrm{cm}^{2}$ ) and membrane permeability (expressed $\mathrm{cm} / \mathrm{s}$ ) data obtained using proximal tubule cell monolayers (e.g. $(41,42)$ ) could all be scaled by surface area for $\mathrm{CL}_{\mathrm{R} \text {,sec }}$ predictions, although has not yet been reported in the literature.

For IVIVE of uptake rates into kidney tissue slices, kidney weight is used as a scaling factor (Table I). Empirical correction was required in order to recover observed $\mathrm{CL}_{\mathrm{R}}$ data following IVIVE of kidney slice uptake data (43). This empirical correction was explained mechanistically as accounting for blood flow-mediated perfusion which is present in vivo but not in the in vitro assay.

Reported models of active secretion and reabsorption have different structures and levels of complexity (14,44-46). Both active secretion and reabsorption can be described using well-stirred or parallel tube models, relating the intrinsic secretion clearance to the renal blood flow (secretion), or the tubular filtrate flow (reabsorption) $(11,22)$. Few studies have compared different structures or refined versions of mechanistic kidney models in specific scenarios $(19,37)$, and further studies of this nature are recommended.

Mechanistic models have recently been developed that incorporate IVIVE of passive tubular reabsorption from in vitro $\mathrm{P}_{\mathrm{app}}$ data $(22,23)$. In these models, tubular surface areas are used as IVIVE scaling factors to convert $\mathrm{P}_{\text {app }}$ data to $\mathrm{CL}_{\text {int }}$ (Table I). An important physiological feature of the kidney is that the tubular filtrate formed at the glomerulus decreases in volume of the along the length of the nephron due fluid reabsorption as its composition changes to become the urine. Models of drug reabsorption in particular should account for the different tubular filtrate flow rates found along different regions of the nephron. This can be achieved by either mathematically describing the simultaneous reabsorption of water and drug along the length of the tubule, or using a model with multiple compartments that each represents a region of the tubule with respective tubular flow rate value $(14,23,47-50)$. The latter approach was applied in models of transporter mediated renal reabsorption of $\gamma$ hydroxybutyric acid in rat $(36,44)$. The advantage of using a multiple compartment model of passive tubular reabsorption 


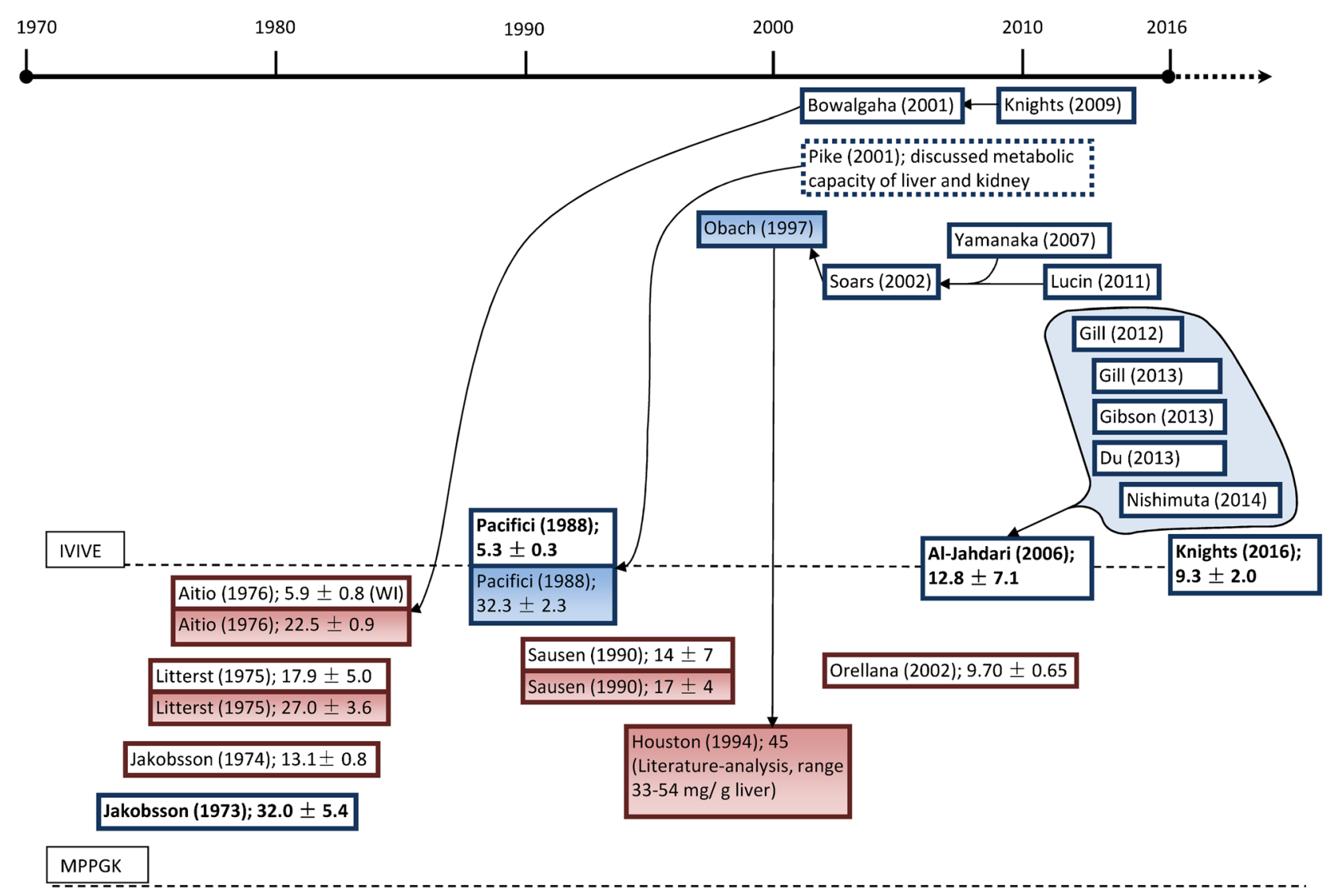

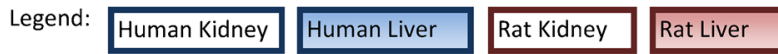

Fig. 1. Chronological presentation of literature reporting experimental measurement of the microsomal protein content in kidney (open boxes) and liver (shaded boxes) for human (blue boxes) and rat (red boxes) (lower section), as well as studies using some of these data to inform the MPPGK scaling factor in order to perform IVIVE of human kidney microsomal metabolism data (upper section). Arrows indicate the cited source of microsomal protein content data used to inform the MPPGK scaling factor for each study. Full references are listed in the supplementary material

is that it can be readily extended to account for metabolism and transport processes in particular compartments. Further validation work and refinements are required for these models of tubular reabsorption to ensure they adequately describe the impact of changes in urine flow rate and $\mathrm{pH}$ on $\mathrm{CL}_{\mathrm{R}}$ for relevant drugs. Notably, altering the tubular filtrate $\mathrm{pH}$ parameters in the dynamic kidney models (e.g. MechKiM in the SimCYP simulator) will change the fraction unionised and subsequently the overall permeability of the total drug (14); however, there is no possibility in this model to specify the $\mathrm{pH}$ at which the in vitro data were generated.

\section{Prediction of Renal Drug-Drug Interactions Within PBPK Paradigm}

Investigation of potential drug-drug interactions during drug development is recognised as an important step towards proper assessment of a drug's safety and effectiveness (51). Decision trees have been proposed for prediction of renal DDIs (51-53) with the main aim to prioritise in vitro and clinical DDI studies, ensuring appropriate labelling requirements are met. Recent studies have reported static models
$(54,55)$ and a PBPK kidney model (14) for prediction of transporter mediated renal DDIs. By using the same transporter kinetics parameters as those reported for the PBPK models $(18,39,40)$, area under the curve (AUC) ratios for renal transporter DDIs with five victim drugs were predicted well using the static model (54) (Fig. 3). AUC ratio predictions were generally in agreement with predictions based on the PBPK approach for three inhibitors investigated, with neither approach providing a clear advantage over the other (Fig. 3). The analysis highlights that if kidney is not relevant with respect to pharmacology or drug toxicity, static models may be sufficient for assessing clinical relevance of renal DDIs mediated by uptake transporters $(54,55)$. The advantages of PBPK kidney models are more apparent when simulating complex DDIs involving multiple organs and mechanisms, including metabolism-transport interplay. The static approach does not support consideration of relationships between uptake, intracellular drug concentrations and efflux of the victim drug. Similarly, when perpetrator drugs exhibit permeability-limited pharmacokinetics, concentrations in relevant compartments should be considered, i.e. intracellular concentrations for efflux transporters and filtrate 


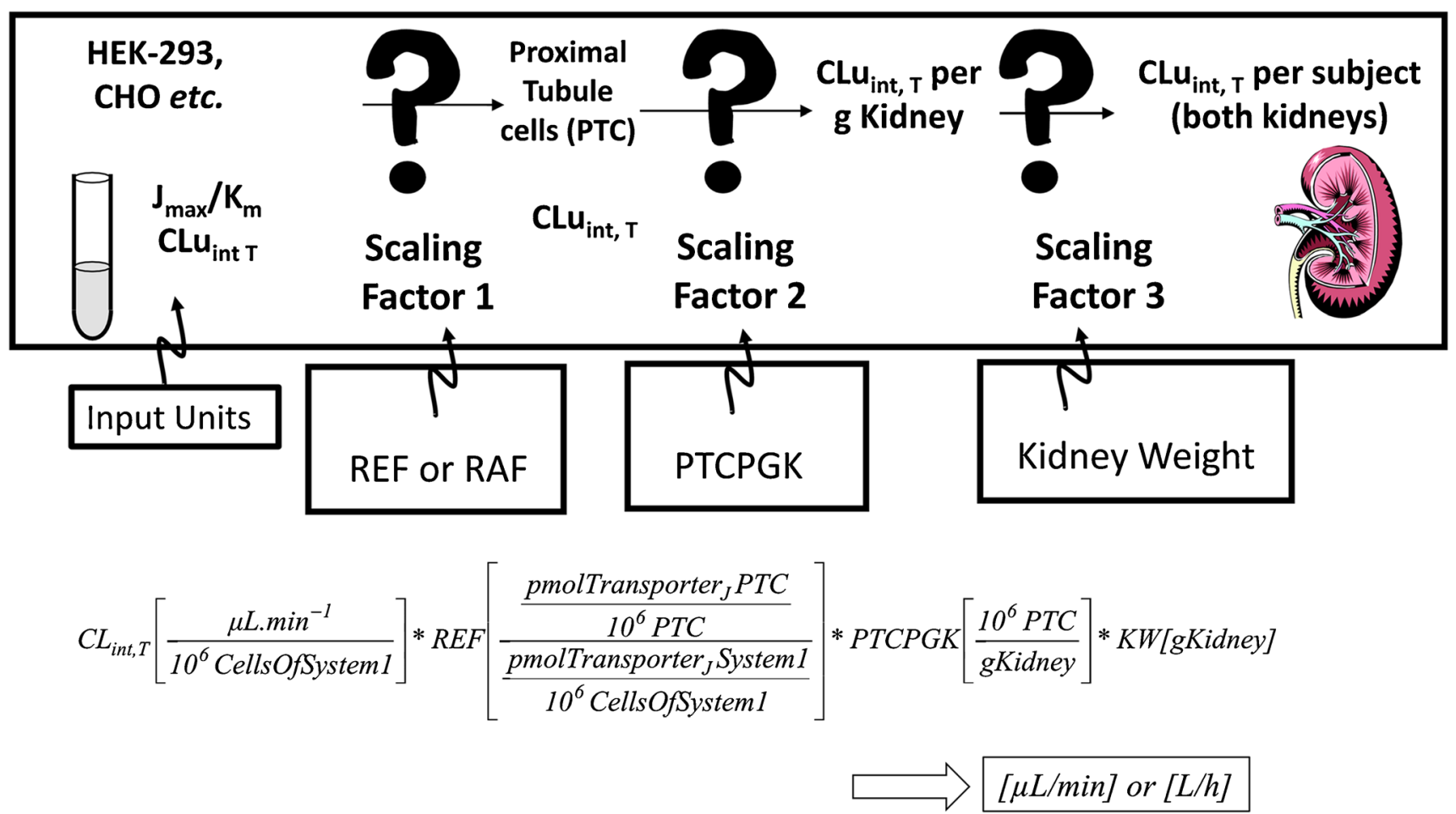

Fig. 2. Proposed IVIVE scaling approach for renal transporter data implemented in the SimCYP MechKiM module. With kind permission from Springer Science+Business Media: Neuhoff et al. (14), Fig. 7.4, page 165.

concentrations for apical uptake transporters. Therefore in cases where there is simultaneous inhibition (or induction) of both uptake and efflux transporter $(18,39,40)$, or renally formed metabolites are perpetrators (as proposed for DDI between non-steroidal anti-inflammatory drugs and methotrexate (57)), the PBPK approach would be favoured for DDI assessment.

\section{Assessing Dosage Adjustment in Chronic Kidney Disease}

Covariate relationships between pharmacokinetic (and/or pharmacodynamics) parameters and demographic information may be used for designing appropriate dose adjustment recommendations for particular population groups (58). For example, statistical analyses of data from clinical pharmacokinetics studies using patients with and without chronic kidney disease can be used to determine whether any relationships between pharmacokinetic parameters (e.g. $\mathrm{CL}_{\mathrm{R}}, \mathrm{CL}, \mathrm{AUC}, \mathrm{V}$ ) and markers of renal function (e.g. creatinine clearance $\left(\mathrm{CL}_{\mathrm{CR}}\right)$ or estimated glomerular filtration rate (eGFR)) exist (59). Such statistical relationships are based on pharmacokinetic parameters obtained from non-compartmental analysis, or in some cases population-pharmacokinetic compartmental modelling is used. While these approaches are currently used during drug development and supported by regulatory bodies $(60,61)$, there are certain limitations. In particular, as limited mechanistic insight is obtained using the statistical approach, predictive extrapolation to untested population groups (e.g. paediatric patients with renal impairment), and therapeutic interventions (e.g. polypharmacy in renally impaired patients) is not possible. By contrast, the possibility to extrapolate into untested scenarios is a key advantage of the PBPK approach $(2,5)$. In addition, the PBPK approach allows for the key mechanisms underpinning altered pharmacokinetics in different pathophysiological states (e.g. diabetes mellitus, acute kidney disease, augmented renal clearance in critically ill, chronic kidney disease) to be investigated and better understood. Regulatory bodies appear open to the prospect of using of PBPK models for prediction of the effect of renal impairment and consideration of any dosage adjustment in this patient population $(39,60)$.

Studies reported to-date using PBPK models have mostly been limited to investigating impact of changes in GFR and plasma protein binding in renally impaired patients on the $\mathrm{CL}_{\mathrm{R}}$ $(39,40,62)$. However, $\mathrm{CL}_{\mathrm{R}}$ may reduce linearly with GFR for many drugs, even when secretion or reabsorption contributes, in accordance with the intact nephron hypothesis $(63,64)$.

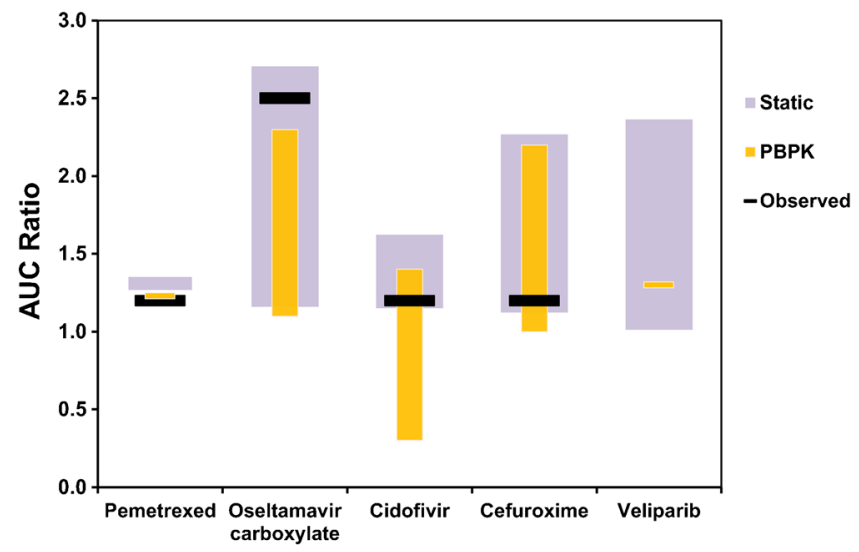

Fig. 3. Comparison of predictions of AUC ratio for renal uptake transporter mediated DDIs with observed data $(39,56)$. AUC ratios were predicted using the static model (54), or taken from published predictions using PBPK model $(18,39,40)$. Full details are listed in the supplementary material, Table S-I 
Accounting for reduced tubular secretion in a physiological manner is challenging, as there are a number of plausible causative mechanisms (65). A simulation study found that reducing the PTCPGK parameter in MechKiM by 15 -fold was needed, in addition to changing GFR, to recover the observed AUC ratio between severe renal impairment and normal renal function subjects (39). However, other potential causes of reduced renal secretion include a downregulation of transporter expression, increased internalisation of renal drug transporters, and inhibition of transporters by uremic toxins that can accumulate in renal impairment (66-68). As accounting for reduced tubular secretion in a mechanistic manner is challenging, an alternative approach is to empirically estimate the extent that tubular secretion is reduced for several drugs, and apply this as a disease-specific scaling factor (69). An analogous approach, involving meta-analysis of relevant clinical data, has been used to understand the impact of renal impairment on the pharmacokinetics of drugs where renal elimination is not the dominant mechanism (e.g. telithromycin) (70). Some additional considerations for PBPK models of renal impairment are discussed below, including the use of virtual populations, relevance of different markers of renal function, and challenges associated with system data collation.

PBPK modelling software such as GastroPlus and SimCYP feature predefined virtual populations and associated system parameters. The categorisation of the moderate and severe renal impairment virtual populations in the SimCYP simulator is based upon the updated GFR cut-off values suggested by the 2010 FDA draft guidance $(61,71)$. However, the cut-off values for these categories are not necessarily relevant to pharmacokinetics, as they were determined for the purpose of diagnosis of kidney disease and the need for therapeutic intervention. In contrast, the more recent guidelines from EMA and recommendations from Kidney Disease: Improving Global Outcomes (KDIGO) suggest that categories used in dose adjustment recommendations should be based upon cut-off values derived from understanding pharmacokinetics and exposure-response $(60,72)$. This approach is particularly important for drugs with narrow therapeutic index such as digoxin (73) and can be achieved by determining the relationships between renal function and pharmacokinetic parameters, considering each as continuous variables rather than categorical variables (72). When using PBPK models, it would therefore be more pragmatic to simulate patients drawn from a single virtual renal impairment population, rather than multiple populations. This should allow more flexibility in data analysis and simpler comparison with clinical data.

Several approaches are available for assessing kidney function, and the advantages and limitation of these were discussed in part I (1). Dosage adjustment recommendations for patients with impairment renal function have historically been based upon creatinine clearance $\left(\mathrm{CL}_{\mathrm{CR}}\right)$, which can either be measured directly following urine collection or estimated from serum creatinine concentrations (61). Dosage adjustment based on estimated glomerular filtration rate (eGFR) is also included in the draft FDA guidance for industry (61), when eGFR is calculated using the modification of diet in renal disease (MDRD) equation from serum creatinine. More recently, a number of equations were developed by the Chronic Kidney Disease Epidemiology Collaboration (CKD-EPI) to estimate GFR from serum creatinine and/or serum cystatin $\mathrm{C}$ (another endogenous substance eliminated primarily by glomerular filtration) (74). Subsequent publications have suggested that CKD-EPI equations are superior to MDRD and $\mathrm{C}-\mathrm{G}$ equations $(75,76)$, and therefore CKD-EPI equations may become more widely used in clinical settings. The latest trend appears to be towards equations that more accurately and precisely estimate GFR, and away from C-G equation for estimating $\mathrm{CL}_{\mathrm{CR}}(60)$. The EMA guidelines propose that the modelling and subsequent dosage adjustment recommendations should have the flexibility to use eGFR or estimated $\mathrm{CL}_{\mathrm{CR}}$ (60). This trend should be encouraged particularly by those developing and using mechanistic kidney models. This is because GFR is a key system parameter in mechanistic kidney models (Part I, (1)), and increased accuracy of physiological data in relevant patients should improve predictive performance of models.

Beyond GFR, lack of relevant physiological data undermines the use of current kidney PBPK models for investigating pharmacokinetic changes in kidney disease (Part I, (1)). Collating these data is challenging, especially because aetiological and/or comorbidity differences between patients with kidney disease could affect the extent or rate at which certain physiological parameters change $(58,77,78)$. This was noted for kidney weight in Part I (Table IV (1)), and it is also proposed that kidney damage can occur without changes in GFR, due to compensation by hyper-filtration in the remaining functional nephrons (79). Furthermore, recent attempts to standardise definitions and classifications of chronic kidney disease and acute kidney injury may confound the collation and categorisation of physiological data taken from historical scientific literature $(80,81)$.

\section{APPROPRIATE CLINICAL DATA ARE NEEDED FOR MODELLING RENAL DRUG ELIMINATION}

\section{Ensuring Parameters Are Identifiable}

Models are often described as 'tools' that are useful for intended purpose. This purpose will determine the criteria used to evaluate a model (as being 'fit-for-purpose') and also the approaches that are permissible for determining values for key parameters in the model. Parameters of PBPK models may be informed solely by in vitro and physiological data through IVIVE (i.e. 'bottom-up'), though fitting to clinical data (i.e. 'top-down') or a combination of both (82). The priority given to ensuring parameters are identifiable will depend upon the both the purpose of the model and the number of parameters that are informed/evaluated by particular clinical datasets. If certain parameters cannot be unambiguously informed from available clinical data then such parameters may be non-identifiable and therefore prone to bias and uncertainty. This problem is well documented for complex mechanistic models and particularly relevant when parameters estimated are to be used for extrapolation (83). Although these issues have been discussed in detail in relation to hepatic disposition $(83,84)$, they are particularly 
pertinent to mechanistic kidney models, due to the high number of parameters used in these models. As knowledge of specific drugs and biological systems are improved, such uncertainties are likely to become reduced, providing more confidence in model predictions $(5,85)$.

It is important to highlight that uncertainty in PBPK model parameter values and/or less-than-perfect accuracy in describing clinical data may not preclude a model from fulfilling its purpose. This may apply in cases where a purely bottom-up approach is applied, and clinical data are not used in the model development. This could also apply in cases where the impact of relative changes (rather than absolute changes) on $\mathrm{CL}_{\mathrm{R}}$ are important. Assessment of relative changes may be useful to determine if certain physiological parameters are more important (e.g. to define the consequence of pathophysiology, investigate effect of change in urine flow rate), and for simulating $\mathrm{CL}_{\mathrm{R}}$ with or without inhibitor effects on certain transporters.

As a specific example, uncertainties in tubular flow rate values were noted during development of a tubular reabsorption model; despite such uncertainty, reasonable prediction of $\mathrm{CL}_{\mathrm{R}}$ for several drugs undergoing extensive tubular reabsorption was achieved (23). Discrepancies between the predicted and observed $\mathrm{CL}_{\mathrm{R}}$ of basic drugs in this study highlighted an area where the mechanistic understanding appears to be incomplete and requires further investigation. Thus when disseminating results from modelling and simulation studies, uncertainties in input parameters or model structure must be recognised up-front to allow audiences to understand the limitations of any conclusions drawn and subsequent simulations that may or may not be possible. Wider debates surrounding parameter identifiability and model evaluation for mechanistic and systems models are ongoing, and interested readers are referred to these publications $(86,87)$.

\section{Renal drug disposition as a result of multiple processes}

In the absence of renal metabolism, $\mathrm{CL}_{\mathrm{R}}$ is determined by a combination of glomerular filtration, active transport into and/ or out of tubular epithelial cells, and passive tubular reabsorption (12). Determining the actual contribution of a given active transport or passive permeability process from typical clinical $\mathrm{CL}_{\mathrm{R}}$ data represents a substantial challenge, even when data from repeated measurement of drug excretion in short intervals in the urine are available. The presence of active tubular secretion can be inferred when $\mathrm{CL}_{\mathrm{R}}$ is greater than the estimated filtration clearance $\left(\mathrm{CL}_{\mathrm{R} \text {, filt }}\right)$, i.e. net secretion, whereas presence of passive or active reabsorption can be inferred when $\mathrm{CL}_{\mathrm{R}}$ is lower than $\mathrm{CL}_{\mathrm{R} \text {,filt }}$. However, a finding of net secretion or net reabsorption for a particular drug does not exclude the possibility of other processes contributing. The presence of such processes can be indicated by alterations in $\mathrm{CL}_{\mathrm{R}}$ in different clinical scenarios. For example, assuming negligible renal metabolism, urine flow rate-dependent $\mathrm{CL}_{\mathrm{R}}$ is a strong indicator for a role of passive tubular reabsorption. For ionised drugs, correlation of changes in $\mathrm{CL}_{\mathrm{R}}$ with urine $\mathrm{pH}$ may be indicative of passive tubular reabsorption of the unionised species, although the potential role of $\mathrm{pH}$-dependent active transport should also be considered in this case. Clinical data from drug-drug interaction studies, whereby $\mathrm{CL}_{\mathrm{R}}$ is altered following co-administration of known transporter inhibitors or inducers, can also provide valuable insight into the processes involved in $\mathrm{CL}_{\mathrm{R}}$ of a drug.

The simultaneous involvement of renal metabolism and excretion may lead to erroneous interpretation of urine drug concentration data (i.e. $\mathrm{CL}_{\mathrm{R}}$ ) if clinical studies are not appropriately designed (12). This can lead to problems for assessment of predictions of $\mathrm{CL}_{\mathrm{R}}$ and renal metabolic clearance $\left(\mathrm{CL}_{\mathrm{R}, \mathrm{met}}\right)$ using IVIVE and other methods. When assessing the contributions of excretory processes, erroneous assumption of negligible renal metabolism can lead to over-estimation of reabsorption and/or under-estimation of secretion. Renal metabolism will decrease the urinary excretion of the parent drug while also contributing to the clearance of parent drug from the plasma. However, a disparity between plasma elimination rate and urinary excretion rate is unlikely to be large enough to be distinguished in order to infer renal drug metabolism, given the variability present in typical pharmacokinetic datasets, and the long periods between urine collections, particularly as hepatic metabolism or other routes of drug elimination may also be present. The isolated perfused kidney model can be used to establish, refine and validate generic IVIVE approaches in preclinical species $(35,88)$. However, species differences can confound translation of preclinical data to the situation in human. Therefore data from clinical studies designed for assessment of intrarenal metabolism are required for validation of IVIVE approaches and mechanistic models.

Several clinical study designs have been reported from which the presence of $\mathrm{CL}_{\mathrm{R} \text {,met }}$ in human has been inferred. Firstly, the rate of appearance of metabolite in urine can be compared with the concentration of metabolite in plasma. If the apparent $\mathrm{CL}_{\mathrm{R}}$ of the metabolite is greater than the renal blood flow or $\mathrm{CL}_{\mathrm{R}}$ of metabolite following direct administration of metabolite alone, this indicates metabolite formation in kidneys $(12,89)$. Secondly, as demonstrated for mycophenolic acid acylglucuronidation, renal metabolism might be inferred after comparison of the AUC of the plasma concentration time profile and renal excretion of the metabolite following i.v. and oral administrations (90). Furthermore, for certain drugs such as propofol, $\mathrm{CL}_{\mathrm{R} \text {,met }}$ has been investigated by analysing plasma drug and/or metabolite concentrations during the anhepatic stage of liver transplant (91). Importantly, the availability of the data from the anhepatic stage enabled IVIVE-PBPK-based predictions of propofol $\mathrm{CL}_{\mathrm{R} \text {,met }}$ and the relative contribution of kidney to overall propofol metabolism to be assessed (33). Finally, lower $\mathrm{CL}_{\mathrm{R}}$ of tacrolimus by cytochrome p450 (CYP) 3A5 expressers compared with non-expressers, along with experimental in vitro data generated using human kidney microsomes, suggests that renal metabolism of tacrolimus is relevant in CYP3A5 expressers (92). In summary, in order to assess predictions of $\mathrm{CL}_{\mathrm{R}}$ and $\mathrm{CL}_{\mathrm{R} \text {,met }}$ using IVIVE and mechanistic kidney models, appropriate clinical data, from carefully designed clinical studies, are required.

\section{Utility and challenges in predicting intracellular concentrations}

An important feature of mechanistic kidney models, particularly PBPK models, is the ability to simulate drug and metabolite concentrations within particular cells/regions. The advantages of this approach have been discussed in general 
terms in previous publications $(93,94)$, and relevance to renal drug toxicity and renal DDIs are highlighted in the sections above and below. However, validating such models can be challenging due to lack of suitable clinical data. For example, models of proximal tubule mediated secretion typically define parameters corresponding to uptake from the plasma into the tubule epithelium, and efflux from the epithelial cells into the tubular filtrate. One of these steps (uptake or efflux) is likely to be rate-limiting; this is often assigned to the uptake parameter in models of renal tubular secretion $(18,39,40)$, although this is not always the case (46). Clinical plasma concentration data alone (where urinary data are not available or adequate) cannot be used to infer which the rate-limiting step is. Plasma data will also be affected by non-renal elimination and distribution processes. When clinical urinary excretion data are also available, this often allows for estimation or validation of either of the uptake or efflux parameters with a higher degree of confidence than plasma data alone. However, given the typical urinary collection intervals, the non-rate-limiting factor often remains nonidentifiable or associated with higher uncertainty $(18,39,40)$. Decreasing time between the urine and plasma sampling events may reduce this problem for some drugs, e.g. by using urinary catheters and/or maintaining diuretic and fluid intake during study $(45,89)$.
An alternative approach for validation or estimation of parameters for both uptake and efflux transporters in a mechanistic kidney model is obtaining intracellular concentration data during clinical studies. Available tools for studying intracellular concentrations have previously been reviewed for liver and are in principle applicable to kidney $(93,95)$. In particular, techniques such as fluorescence confocal microscopy and imaging mass spectrometry enable assessment of intracellular drug concentrations in tissue following animal in vivo studies $(96,97)$. For clinical development, positron emission tomography (PET) imaging may be a useful tool, although spatial resolution is not particularly high, and metabolites are indistinguishable from parent drug using this technique, which could confound interpretation of such data (98).

As these features are not typically included in clinical trial design, more frequently the parameter that is not the rate-limiting step is set to a very high value, and then the clinical data are used to estimate/validate only the ratelimiting transport parameter $(18,46)$. If uptake is the nonidentifiable parameter, this will require that efflux from the cell to the blood is also parameterised in order to prevent simulation of unlimited accumulation of drug within the proximal tubule cell, effectively resulting in blood-flow

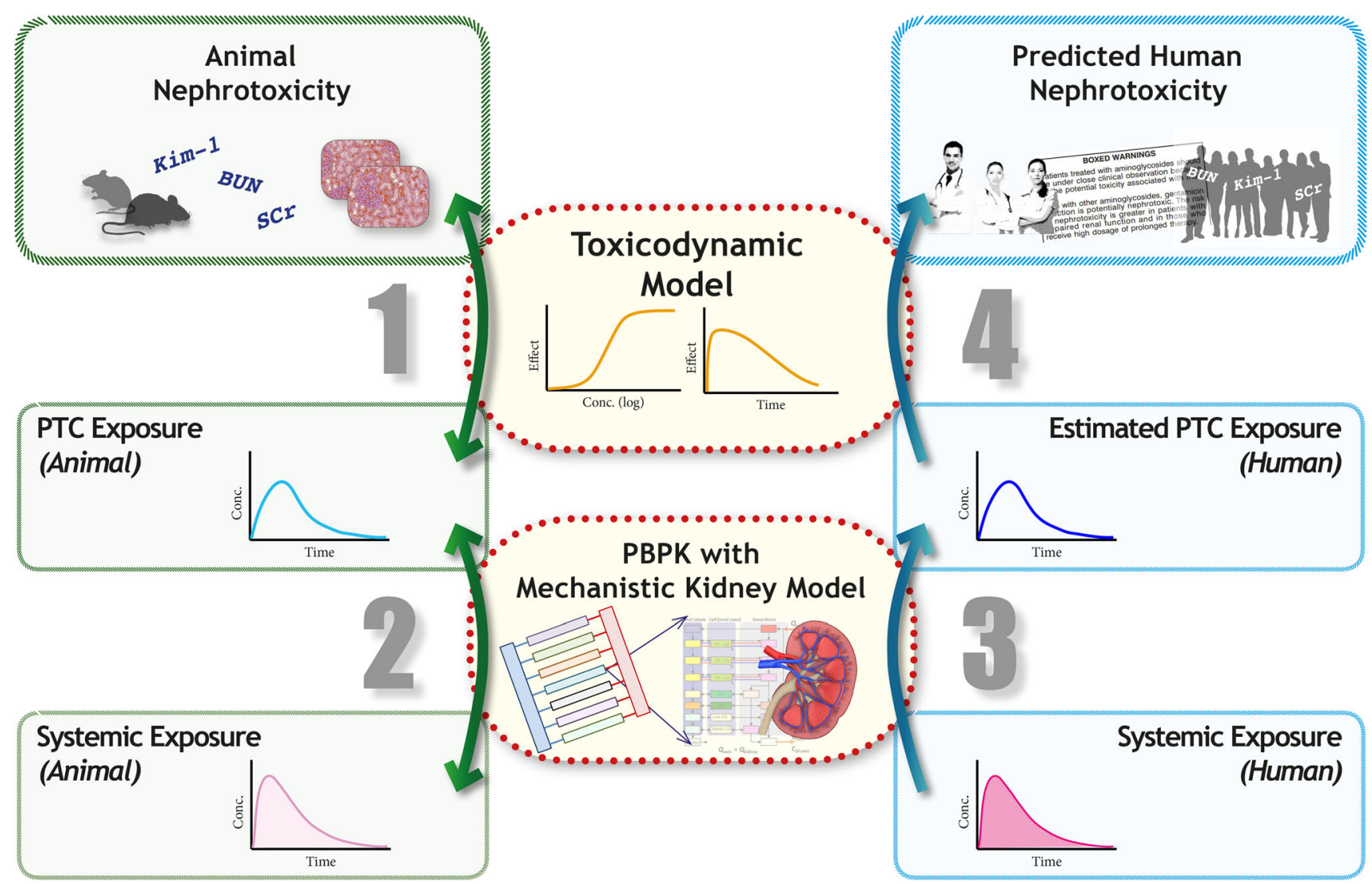

Fig. 4. Proposed framework for applying physiologically based pharmacokinetic (PBPK) kidney models for prediction of nephrotoxicity risk in human following translation of in vivo studies in preclinical species. The steps involve: [1] Carrying out nephrotoxicity studies in lab animals and establish relationship between toxicity biomarkers and measured proximal tubule cell (PTC) drug concentrations. [2] Constructing PBPK kidney model to mechanistically describe relationship between drug concentrations measured in proximal tubule cells and systemic circulation in animal. [3] Estimating the doses which may lead to nephrotoxic drug exposure in human proximal tubule cells using the PBPK model, after accounting for relevant species differences in renal physiology (e.g. GFR, blood flow, renal drug transporter expression/substrate affinity (1)). [4] Accounting for any potential species differences in the apparent toxicodynamics in the prediction of human nephrotoxicity risk from estimated proximal tubule cell exposure (by linking the effect to the concentration at the site of the effect) 
limited uptake into the cells (46). If an uptake or efflux transporter parameter is non-identifiable, then subsequent simulations of proximal tubule cellular concentrations and extrapolation involving this non-identifiable parameter (e.g. special populations, DDIs) will not be quantitatively meaningful (see above).

\section{CONCLUSION AND FUTURE DIRECTIONS}

The possibility for simulating a myriad of scenarios is a key strength of mechanistic kidney models. Such models may have promising applications including assessment of DDIs and impact of pathophysiology as described above, as well as investigation of drug-induced nephrotoxicity. For example, a framework that may lead to improved translation of preclinical species nephrotoxicity studies for prediction of toxicity risk in human is suggested here, as presented in Fig. 4. This framework provides the opportunity to account for species differences in renal physiology (e.g. drug transporter expression (1)) that may affect drug exposure at sites of potential toxicity (e.g. proximal tubule cells). This is not possible when using pharmacokinetic-toxicodynamic models because they directly link toxicity to systemic exposure (or dose), which may not reflect local exposure. It is proposed that in this framework, known species differences in renal physiology will be accounted for using PBPK kidney models (Fig. 4). Practical applications of this are anticipated as part of many ongoing research activities such as Horizon 2020 or Innovative Medicines Initiatives (IMI) projects, and will require improvements in measurement of intracellular drug concentrations from in vivo studies, as described above.

The application of bottom-up approaches such as IVIVE to inform PBPK model parameters helps in overcoming challenges that are encountered when fitting such complex models to clinical data. From the modelling perspective, the dependency on data taken from disparate literature sources, presented in a variety of ways, can be a profound limitation. In this sense, the reporting of basic inter-system scalars for in vitro systems (e.g. number of cells per $\mathrm{cm}^{2}, \mathrm{mg}$ protein per million cells, etc.) alongside activity or abundance data by laboratory-based scientists, which is not currently common practice, could be of assistance to those using mechanistic models.

In Part I of this review, gaps in our knowledge of physiologically based scaling factors was discussed, and has been highlighted here as a key limitation of IVIVE-PBPK in kidney (1). Much attention is being given to the promise of quantitative proteomics as a means to determine REF scalars by measuring protein abundances in tissue samples and in vitro systems $(17,21,99)$. However, abundance data are currently scarce due to limited use of mass spectrometrybased quantitative proteomics outside of specialist academic laboratories (1), and may not represent all variations in patients who are the target of drug treatment. In addition, protein abundance may not accurately reflect activity (e.g. recycling of transporters between the plasma membrane and an intracellular pool (100)). Therefore additional activity data are currently needed to determine whether activity-based scalars (ISEF, RAF) will be required in addition to or instead of REFs. Generating relevant activity data for this requires specific substrates that can be used both in vitro and in vivo. This is a problem for transporters, which can exhibit marked overlap in substrate specificity (101). Metabolomics approaches could be useful for identifying highly specific endogenous substrates of transporters that would be suitable for characterisation of activity in vivo (102).

Further refinement of mechanistic modelling of transporter kinetics may result in a more mechanistic input in PBPK kidney models, as illustrated with consideration of electrochemical gradient on organic cation (OCT) mediated uptake of metformin (19). Other features of transporter kinetics that may be considered in the future include role of ATP concentrations, impact of concentration gradients ( $\mathrm{pH}$, sodium or other ions) and differences between antiporters and symporters.

There is an urgent need for suitable clinical data to validate various elements of IVIVE-PBPK for renal drug disposition. This includes data suitable for distinction of renal drug metabolism from renal excretion and/or non-renal drug metabolism and for validation/estimation of uptake and efflux transport rate parameters, as described above. Enhanced clinical trial design may be warranted to study relevant drugs, including rich sampling of urine and plasma, measurement of metabolite concentrations in plasma and urine, and assessment of intracellular or tissue concentrations.

In conclusion, the complexities involved in mechanistically modelling renal drug disposition within the framework of IVIVEPBPK were discussed. Many challenges were identified, such as knowledge gaps in physiological data and the need to refine and characterise in vitro systems (see Part I, (1)), and requirement for suitable clinical data. However, the tangible benefits (e.g. safe dosage adjustment in renal impairment/paediatric patients, prediction of renal DDIs, prediction of nephrotoxicity risk) justify the efforts required to meet these challenges, and thereby make mechanistic modelling of kidneys a success.

\section{ACKNOWLEDGMENTS}

D.S. was supported by a PhD studentship from the Biotechnology and Biological Sciences Research Council UK (BB/J500379/1) and AstraZeneca, Cambridge, UK. Part of this work was presented at AAPS Annual Meeting 2015, Orlando, FL. The authors would like to acknowledge the assistance of Eleanor Savill in preparing this manuscript.

Open Access This article is distributed under the terms of the Creative Commons Attribution 4.0 International License (http://creativecommons.org/licenses/by/4.0/), which permits unrestricted use, distribution, and reproduction in any medium, provided you give appropriate credit to the original author(s) and the source, provide a link to the Creative Commons license, and indicate if changes were made.

\section{REFERENCES}

1. Scotcher D, Jones C, Posada MM, Rostami-Hodjegan A, Galetin A. Key to opening kidney for in vitro-in vivo extrapolation entrance in health and disease: Part I: in vitro systems and physiological data. AAPS J. 2016. doi:10.1208/s12248-016-9942-x.

2. Rostami-Hodjegan A. Physiologically based pharmacokinetics joined with in vitro-in vivo extrapolation of ADME: a marriage under the arch of systems pharmacology. Clin Pharmacol Ther. 2012;92:50-61. 
3. Paine SW, Ménochet K, Denton R, McGinnity DF, Riley RJ. Prediction of human renal clearance from preclinical species for a diverse set of drugs that exhibit both active secretion and net reabsorption. Drug Metab Dispos. 2011;39:1008-13.

4. Jadhav PR, Cook J, Sinha V, et al. A proposal for scientific framework enabling specific population drug dosing recommendations. J Clin Pharmacol. 2015;55:1073-8.

5. Wagner C, Zhao P, Pan Y, et al. Application of physiologically based pharmacokinetic (PBPK) modeling to support dose selection: report of an FDA public workshop on PBPK. CPT Pharmacometrics Syst Pharmacol. 2015;4:226-30.

6. European Medicines Agency. Reflection paper on extrapolation of efficacy and safety in paediatric medicine development (Draft; EMA/199678/2016). London: European Medicines Agency; 2016.

7. Hayton WL. Maturation and growth of renal function: dosing renally cleared drugs in children. AAPS PharmSci. 2000;2:22-8.

8. Edginton AN, Schmitt W, Voith B, Willmann S. A mechanistic approach for the scaling of clearance in children. Clin Pharmacokinet. 2006;45:683-704.

9. Alcorn J, McNamara PJ. Ontogeny of hepatic and renal systemic clearance pathways in infants part I. Clin Pharmacokinet. 2002;41:959-98.

10. Takashima T, Wu C, Takashima-Hirano M, et al. Evaluation of breast cancer resistance protein function in hepatobiliary and renal excretion using PET with 11C-SC-62807. J Nucl Med. 2013;54:267-76.

11. Janků I. Physiological modelling of renal drug clearance. Eur J Clin Pharmacol. 1993;44:513-9.

12. Tucker G. Measurement of the renal clearance of drugs. Br J Clin Pharmacol. 1981;12:761-70.

13. Zamek-Gliszczynski MJ, Lee CA, Poirier A, et al. ITC recommendations for transporter kinetic parameter estimation and translational modeling of transport-mediated PK and DDIs in humans. Clin Pharmacol Ther. 2013;94:64-79.

14. Neuhoff S, Gaohua L, Burt H, et al. Accounting for transporters in renal clearance: towards a mechanistic kidney model (Mech KiM). In: Sugiyama Y, Bente S, editors. Transporters in drug development. New York: Springer; 2013. p. 155-77.

15. Houston JB. Utility of in vitro drug metabolism data in predicting in vivo metabolic clearance. Biochem Pharmacol. 1994;47:1469-79.

16. Nishimuta H, Houston JB, Galetin A. Hepatic, intestinal, renal, and plasma hydrolysis of prodrugs in human, cynomolgus monkey, dog, and rat: implications for in vitro-in vivo extrapolation of clearance of prodrugs. Drug Metab Dispos. 2014;42:1522-31.

17. Knights KM, Spencer SM, Fallon JK, Chau N, Smith PC, Miners JO. Scaling factors for the in vitro-in vivo extrapolation (IV-IVE) of renal drug and xenobiotic glucuronidation clearance. Br J Clin Pharmacol. 2016. doi:10.1111/bcp.12889.

18. Posada MM, Bacon JA, Schneck KB, et al. Prediction of renal transporter mediated drug-drug interactions for Pemetrexed using physiologically based pharmacokinetic modeling. Drug Metab Dispos. 2015;43:325-34.

19. Burt HJ, Neuhoff S, Almond L, et al. Metformin and cimetidine: physiologically based pharmacokinetic modelling to investigate transporter mediated drug-drug interactions. Eur J Pharm Sci. 2016;88:70-82.

20. Gibson CR, Lu P, Maciolek C, et al. Using human recombinant UDP-glucuronosyltransferase isoforms and a relative activity factor approach to model total body clearance of laropiprant (MK-0524) in humans. Xenobiotica. 2013:43:1027-36.

21. Nakamura K, Hirayama-Kurogi M, Ito S, et al. Large-scale multiplex absolute protein quantification of drug-metabolizing enzymes and transporters in human intestine, liver and kidney microsomes by SWATH-MS: comparison with MRM/SRM and HR-MRM/PRM. Proteomics. 2016. doi:10.1002/pmic.201500433.

22. Kunze A, Huwyler J, Poller B, Gutmann H, Camenisch G. In vitro-in vivo extrapolation method to predict human renal clearance of drugs. J Pharm Sci. 2014;103:994-1001.

23. Scotcher D, Jones C, Rostami-Hodjegan A, Galetin A. Novel minimal physiologically-based model for the prediction of passive tubular reabsorption and renal excretion clearance. Eur J Pharm Sci. 2016. doi:10.1016/j.ejps.2016.03.018.

24. Watanabe T, Kusuhara H, Debori Y, et al. Prediction of the overall renal tubular secretion and hepatic clearance of anionic drugs and a renal drug-drug interaction involving organic anion transporter 3 in humans by in vitro uptake experiments. Drug Metab Dispos. 2011;39:1031-8.

25. Al-Jahdari WS, Yamamoto K, Hiraoka H, Nakamura K, Goto F, Horiuchi R. Prediction of total propofol clearance based on enzyme activities in microsomes from human kidney and liver. Eur J Clin Pharmacol. 2006;62:527-33.

26. Barter ZE, Chowdry JE, Harlow JR, Snawder JE, Lipscomb JC, Rostami-Hodjegan A. Covariation of human microsomal protein per gram of liver with age: absence of influence of operator and sample storage may justify interlaboratory data pooling. Drug Metab Dispos. 2008;36:2405-9.

27. Fallon JK, Neubert H, Goosen TC, Smith PC. Targeted precise quantification of 12 human recombinant uridine-diphosphate glucuronosyl transferase $1 \mathrm{~A}$ and $2 \mathrm{~B}$ isoforms using nano-ultrahigh-performance liquid chromatography/tandem mass spectrometry with selected reaction monitoring. Drug Metab Dispos. 2013;41:2076-80.

28. Sato Y, Nagata M, Tetsuka K, et al. Optimized methods for targeted peptide-based quantification of human uridine $5^{\prime}$-diphosphateglucuronosyltransferases in biological specimens using liquid chromatography-tandem mass spectrometry. Drug Metab Dispos. 2014;42:885-9.

29. Zhang H, Patana A-S, Mackenzie PI, Ikushiro S, Goldman A, Finel $M$. Human UDP-glucuronosyltransferase expression in insect cells: ratio of active to inactive recombinant proteins and the effects of a C-terminal his-tag on glucuronidation kinetics. Drug Metab Dispos. 2012:40:1935-44.

30. Miners JO, Mackenzie PI, Knights KM. The prediction of drugglucuronidation parameters in humans: UDP-glucuronosyltransferase enzyme-selective substrate and inhibitor probes for reaction phenotyping and in vitro-in vivo extrapolation of drug clearance and drugdrug interaction potential. Drug Metab Rev. 2010;42:196-208.

31. Walsky RL, Bauman JN, Bourcier K, et al. Optimized assays for human UDP-glucuronosyltransferase (UGT) activities: altered alamethicin concentration and utility to screen for UGT inhibitors. Drug Metab Dispos. 2012;40:1051-65.

32. Gill KL, Houston JB, Galetin A. Characterization of in vitro glucuronidation clearance of a range of drugs in human kidney microsomes: comparison with liver and intestinal glucuronidation and impact of albumin. Drug Metab Dispos. 2012;40:825-35.

33. Gill KL, Gertz M, Houston JB, Galetin A. Application of a physiologically based pharmacokinetic model to assess propofol hepatic and renal glucuronidation in isolation: utility of in vitro and in vivo data. Drug Metab Dispos. 2013;41:744-53.

34. de Lannoy IA, Hirayama H, Pang KS. A physiological model for renal drug metabolism: enalapril esterolysis to enalaprilat in the isolated perfused rat kidney. J Pharmacokinet Biopharm. 1990;18:561-87.

35. Geng W, Pang KS. Differences in excretion of hippurate, as a metabolite of benzoate and as an administered species, in the singlepass isolated perfused rat kidney explained. J Pharmacol Exp Ther. 1999;288:597-606

36. Dave RA, Morris ME. Semi-mechanistic kidney model incorporating physiologically-relevant fluid reabsorption and transporter-mediated renal reabsorption: pharmacokinetics of $\gamma$-hydroxybutyric acid and 1-lactate in rats. J Pharmacokinet Pharmacodyn. 2015;42:497-513.

37. Felmlee MA, Dave RA, Morris ME. Mechanistic models describing active renal reabsorption and secretion: a simulation-based study. AAPS J. 2013;15:278-87.

38. Bentz J, O'Connor MP, Bednarczyk D, et al. Variability in Pglycoprotein inhibitory potency (IC50) using various in vitro experimental systems: implications for universal digoxin drug-drug interaction risk assessment decision criteria. Drug Metab Dispos. 2013;41:1347-66.

39. Hsu V, de LT Vieira M, Zhao P, et al. Towards quantitation of the effects of renal impairment and probenecid inhibition on kidney uptake and efflux transporters, using physiologically based pharmacokinetic modelling and simulations. Clin Pharmacokinet. 2014;53:283-93.

40. Li J, Kim S, Sha X, Wiegand R, Wu J, LoRusso P. Complex disease-, gene-, and drug-drug interactions: impacts of renal function, CYP2D6 phenotype, and OCT2 activity on veliparib pharmacokinetics. Clin Cancer Res. 2014;20:3931-44. 
41. Wilmer MJ, Saleem MA, Masereeuw R, et al. Novel conditionally immortalized human proximal tubule cell line expressing functional influx and efflux transporters. Cell Tissue Res. 2010;339:449-57.

42. Brown CD, Sayer R, Windass AS, et al. Characterisation of human tubular cell monolayers as a model of proximal tubular xenobiotic handling. Toxicol Appl Pharmacol. 2008;233:428-38.

43. Watanabe T, Maeda K, Kondo T, et al. Prediction of the hepatic and renal clearance of transporter substrates in rats using in vitro uptake experiments. Drug Metab Dispos. 2009;37:1471-9.

44. Felmlee MA, Wang Q, Cui D, Roiko SA, Morris ME. Mechanistic toxicokinetic model for $\gamma$-hydroxybutyric acid: inhibition of active renal reabsorption as a potential therapeutic strategy. AAPS J. 2010;12:407-16.

45. Russel FG, Wouterse AC, van Ginneken CA. Physiologically based pharmacokinetic model for the renal clearance of phenolsulfonphthalein and the interaction with probenecid and salicyluric acid in the dog. J Pharmacokinet Biopharm. 1987;15:349-68.

46. Ogungbenro K, Aarons L. Physiologically based pharmacokinetic modelling of methotrexate and 6-mercaptopurine in adults and children. Part 1: methotrexate. J Pharmacokinet Pharmacodyn. 2014;41:159-71.

47. Mayer JM, Hall SD, Rowland M. Relationship between lipophilicity and tubular reabsorption for a series of 5-alkyl-5-ethylbarbituric acids in the isolated perfused rat kidney preparation. J Pharm Sci. 1988;77:359-64.

48. Hall S, Rowland M. Relationship between renal clearance, protein binding and urine flow for digitoxin, a compound of low clearance in the isolated perfused rat kidney. J Pharmacol Exp Ther. 1984;228:174-9.

49. Tang-Liu D, Tozer TN, Riegelman S. Dependence of renal clearance on urine flow: a mathematical model and its application. J Pharm Sci. 1983;72:154-8.

50. Komiya I. Urine flow dependence of renal clearance and interrelation of renal reabsorption and physicochemical properties of drugs. Drug Metab Dispos. 1986;14:239.

51. US Food Drug Admin. Guidance for industry: drug interaction studies - study design, data analysis, implications for dosing, and labeling recommendations. Silver Spring: US Food and Drug Administration; 2012.

52. Tweedie D, Polli JW, Berglund EG, et al. Transporter studies in drug development: experience to date and follow-up on decision trees from the international transporter consortium. Clin Pharmacol Ther. 2013;94:113-25.

53. European Medicines Agency. Guideline on the investigation of drug interactions (CPMP/EWP/560/95/Rev. 1 Corr. 2). London: Committee for Human Medicinal Products (CHMP); 2012.

54. Feng B, Hurst S, Lu Y, et al. Quantitative prediction of renal transporter-mediated clinical drug-drug interactions. Mol Pharm. 2013;10:4207-15.

55. Maeda K, Tian Y, Fujita $\mathrm{T}$, et al. Inhibitory effects of paminohippurate and probenecid on the renal clearance of adefovir and benzylpenicillin as probe drugs for organic anion transporter (OAT) 1 and OAT3 in humans. Eur J Pharm Sci. 2014;59:94-103.

56. Sweeney CJ, Takimoto CH, Latz JE, et al. Two drug interaction studies evaluating the pharmacokinetics and toxicity of pemetrexed when coadministered with aspirin or ibuprofen in patients with advanced cancer. Clin Cancer Res. 2006;12:536-42.

57. Kawase A, Yamamoto T, Egashira S, Iwaki M. Stereoselective inhibition of methotrexate excretion by glucuronides of nonsteroidal anti-inflammatory drugs via multidrug resistance proteins 2 and 4. J Pharmacol Exp Ther. 2016;356:366-74.

58. Tortorici MA, Cutler DL, Hazra A, Nolin TD, Rowland-Yeo K, Venkatakrishnan K. Emerging areas of research in the assessment of pharmacokinetics in patients with chronic kidney disease. J Clin Pharmacol. 2015;55:241-50.

59. Jonckheere S, De Neve N, De Beenhouwer H, Berth M, Vermeulen A, Van Bocxlaer J, et al. A model-based analysis of the predictive performance of different renal function markers for cefepime clearance in the ICU. J Antimicrob Chemother. 2016:dkw171.

60. European Medicines Agency. Guideline on the evaluation of the pharmacokinetics of medicinal products in patients with decreased renal function (EMA/83874/2014). London: Committee for Human Medicinal Products (CHMP); 2014.

61. US Food Drug Admin. Guidance for industry: pharmacokinetics in patients with impaired renal function—study design, data analysis, and impact on dosing and labeling (Revision 1). Silver Spring: US Food and Drug Administration; 2010.

62. Rodieux F, Wilbaux M, van den Anker JN, Pfister M. Effect of kidney function on drug kinetics and dosing in neonates, infants, and children. Clin Pharmacokinet. 2015;54:1183-204.

63. Bricker NS, Morrin PA, Kime SW. The pathologic physiology of chronic Bright's disease: an exposition of the "intact nephron hypothesis". Am J Med. 1960;28:77-98.

64. Sayama H, Takubo H, Komura H, Kogayu M, Iwaki M. Application of a physiologically based pharmacokinetic model informed by a topdown approach for the prediction of pharmacokinetics in chronic kidney disease patients. AAPS J. 2014;16:1018-28.

65. Sun H, Frassetto L, Benet LZ. Effects of renal failure on drug transport and metabolism. Pharmacol Ther. 2006;109:1-11.

66. Mutsaers HA, Van Den Heuvel LP, Ringens LH, et al. Uremic toxins inhibit transport by breast cancer resistance protein and multidrug resistance protein 4 at clinically relevant concentrations. PLoS ONE. 2011;6, e18438.

67. Naud J, Michaud J, Beauchemin S, et al. Effects of chronic renal failure on kidney drug transporters and cytochrome P450 in rats. Drug Metab Dispos. 2011;39:1363-9.

68. Nigam SK, Wu W, Bush KT, Hoenig MP, Blantz RC, Bhatnagar V. Handling of drugs, metabolites, and uremic toxins by kidney proximal tubule drug transporters. Clin J Am Soc Nephrol. 2015;10:2039-49.

69. Vogt W. Evaluation and optimisation of current milrinone prescribing for the treatment and prevention of low cardiac output syndrome in paediatric patients after open heart surgery using a physiology-based pharmacokinetic drug-disease model. Clin Pharmacokinet. 2014;53:51-72.

70. Rowland Yeo K, Aarabi M, Jamei M, Rostami-Hodjegan A. Modeling and predicting drug pharmacokinetics in patients with renal impairment. Expert Rev Clin Pharmacol. 2011;4:261-74.

71. US Food Drug Admin. In: Services UDoHaH, editor. Guidance for industry: pharmacokinetics in patients with impaired renal function - study design, data analysis, and impact on dosing and labeling. Rockville: US Food and Drug Administration; 1998.

72. Matzke GR, Aronoff GR, Atkinson AJ, et al. Drug dosing consideration in patients with acute and chronic kidney disease- $\mathrm{a}$ clinical update from Kidney Disease: Improving Global Outcomes (KDIGO). Kidney Int. 2011;80:1122-37.

73. Concordia Pharmaceuticals Inc. Highlights of prescribing information: lanoxin-digoxin tablet [Retrieved from http://labels.fda.gov/, May 23, 2016]: St. Michael, Barbados; 2015.

74. Inker LA, Schmid $\mathrm{CH}$, Tighiouart $\mathrm{H}$, et al. Estimating glomerular filtration rate from serum creatinine and cystatin C. $N$ Engl J Med. 2012;367:20-9.

75. Kilbride HS, Stevens PE, Eaglestone G, et al. Accuracy of the MDRD (modification of diet in renal disease) study and CKD-EPI (CKD epidemiology collaboration) equations for estimation of GFR in the elderly. Am J Kidney Dis. 2013;61:57-66.

76. Delanaye P, Mariat C. The applicability of eGFR equations to different populations. Nat Rev Nephrol. 2013;9:513-22.

77. Jameson K, Jick S, Hagberg K, Ambegaonkar B, Giles A, O'Donoghue D. Prevalence and management of chronic kidney disease in primary care patients in the UK. Int J Clin Pract. 2014;68:1110-21.

78. Levey AS, Coresh J, Balk E, et al. National kidney foundation practice guidelines for chronic kidney disease: evaluation, classification, and stratification. Ann Intern Med. 2003;139:137-47.

79. Schnaper HW. Remnant nephron physiology and the progression of chronic kidney disease. Pediatr Nephrol. 2014;29:193-202.

80. Levey AS, de Jong PE, Coresh J, et al. The definition, classification, and prognosis of chronic kidney disease: a KDIGO controversies conference report. Kidney Int. 2011;80:17-28.

81. Leung KC, Tonelli M, James MT. Chronic kidney disease following acute kidney injury-risk and outcomes. Nat Rev Nephrol. 2013;9:77-85.

82. Jones H, Chen Y, Gibson C, et al. Physiologically based pharmacokinetic modeling in drug discovery and development: a pharmaceutical industry perspective. Clin Pharmacol Ther. 2015;97:247-62.

83. Tsamandouras N, Rostami-Hodjegan A, Aarons L. Combining the 'bottom up'and 'top down' approaches in pharmacokinetic modelling: fitting PBPK models to observed clinical data. Br J Clin Pharmacol. 2015;79:48-55. 
84. Gertz M, Tsamandouras N, Säll C, Houston JB, Galetin A. Reduced physiologically-based pharmacokinetic model of repaglinide: impact of OATP1B1 and CYP2C8 genotype and source of in vitro data on the prediction of drug-drug interaction risk. Pharm Res. 2014;31:2367-82.

85. Rowland M, Lesko L, Rostami-Hodjegan A. Physiologically based pharmacokinetics is impacting drug development and regulatory decision making. CPT Pharmacometrics Syst Pharmacol. 2015;4:313-5.

86. Friedrich C. A model qualification method for mechanistic physiological QSP models to support model-informed drug development. CPT Pharmacometrics Syst Pharmacol. 2016;5:43-53.

87. Agoram B. Evaluating systems pharmacology models is different from evaluating standard pharmacokinetic-pharmacodynamic models. CPT Pharmacometrics Syst Pharmacol. 2014;3:1-3.

88. Wang J, Evans AM, Knights KM, Miners JO. Differential disposition of intra-renal generated and preformed glucuronides: studies with 4-methylumbelliferone and 4-methylumbelliferyl glucuronide in the filtering and nonfiltering isolated perfused rat kidney. J Pharm Pharmacol. 2011;63:507-14.

89. Vree T, Kolmer EE-B, Wuis E, Hekster Y, Broekman M. Interindividual variation in the capacity-limited renal glucuronidation of probenecid by humans. Pharm World Sci. 1993; $15: 197-202$.

90. Bullingham R, Monroe S, Nicholls A, Hale M. Pharmacokinetics and bioavailability of mycophenolate mofetil in healthy subjects after single-dose oral and intravenous administration. J Clin Pharmacol. 1996;36:315-24.

91. Veroli P, O’Kelly B, Bertrand F, Trouvin J, Farinotti R, Ecoffey C. Extrahepatic metabolism of propofol in man during the anhepatic phase of orthotopic liver transplantation. Br J Anaesth. 1992;68:183-6.

92. Zheng S, Tasnif Y, Hebert MF, et al. CYP3A5 gene variation influences both systemic and intrarenal tacrolimus disposition. Clin Pharmacol Ther. 2012;92:737.
93. Chu X, Korzekwa K, Elsby R, et al. Intracellular drug concentrations and transporters: measurement, modeling, and implications for the liver. Clin Pharmacol Ther. 2013;94:126-41.

94. Hamon J, Renner M, Jamei M, Lukas A, Kopp-Schneider A, Bois FY. Quantitative in vitro to in vivo extrapolation of tissues toxicity. Toxicol In Vitro. 2015;30:203-16.

95. Dollery C. Intracellular drug concentrations. Clin Pharmacol Ther. 2013;93:263-6.

96. Nagle MA, Truong DM, Dnyanmote AV, et al. Analysis of threedimensional systems for developing and mature kidneys clarifies the role of OAT1 and OAT3 in antiviral handling. J Biol Chem. 2011;286:243-51.

97. Takai N, Tanaka Y, Saji H. Quantification of small molecule drugs in biological tissue sections by imaging mass spectrometry using surrogate tissue-based calibration standards. Mass Spectrom (Tokyo). 2014;3:A0025.

98. Matthews PM, Rabiner EA, Passchier J, Gunn RN. Positron emission tomography molecular imaging for drug development. Br J Clin Pharmacol. 2012;73:175-86.

99. Al Feteisi H, Achour B, Rostami-Hodjegan A, Barber J. Translational value of liquid chromatography coupled with tandem mass spectrometry-based quantitative proteomics for in vitro-in vivo extrapolation of drug metabolism and transport and considerations in selecting appropriate techniques. Expert Opin Drug Metab Toxicol. 2015;11:1357-69.

100. Wolff NA, Thies K, Kuhnke N, et al. Protein kinase C activation downregulates human organic anion transporter 1-mediated transport through carrier internalization. J Am Soc Nephrol. 2003;14:1959-68.

101. El-Sheikh AA, Masereeuw R, Russel FG. Mechanisms of renal anionic drug transport. Eur J Pharmacol. 2008;585:245-55.

102. Kienana M, Benz-de Bretagne I, Nadal-Desbarats L, et al. Endogenous metabolites that are substrates of organic anion transporter's (OATs) predict methotrexate clearance. Pharmacol Res. 2016. doi:10.1016/j.phrs.2016.05.021. 